\title{
Preparation of Novel Polymer Hybrids from Imogolite Nanofiber
}

\author{
Kazuya Yамамото, Hideyuki OtsUKA, and Atsushi TAKAHARA ${ }^{\dagger}$ \\ Institute for Materials Chemistry and Engineering, Kyushu University, \\ 6-10-1 Hakozaki, Higashi-ku, Fukuoka 812-8581, Japan
}

(Received October 10, 2006; Accepted October 27, 2006; Published December 7, 2006)

\begin{abstract}
Polymer hybrids designed on a nanometer scale were prepared by several methods with an aluminosilicate nanofiber, "imogolite." This review paper introduces the preparation of polymer hybrid materials from imogolite nanofiber by two different approaches. In order to realize the fine dispersion of imogolite in polymer matrix, poly(vinyl alcohol)/imogolite hybrids were prepared by in situ synthesis method of imogolite in polymer solution. In addition, through utilizing the strong interaction between phosphoric acid group and Al-OH on the surface of imogolite, poly(methyl methacrylate)/imogolite hybrid, and enzyme/imogolite hybrid gel were prepared and characterized. [doi:10.1295/polymj.PJ2006128]
\end{abstract}

KEY WORDS Imogolite / Hybrid / Surface Modification / In Situ Synthesis / Phosphoric Acid /

Imogolite is a hydrous aluminosilicate nanofiber, that was found in naturally occurring weathered pumice beds of volcanic ash soil ("Imogolayer") in Kyushu, Japan, in 1962. ${ }^{1}$ Imogolite with the general formula of $\left[\mathrm{Al}_{2} \mathrm{O}_{3} \cdot \mathrm{SiO}_{2} \cdot 2 \mathrm{H}_{2} \mathrm{O}\right]$ forms a hollow nanotube with an external diameter of $c a .2 .5 \mathrm{~nm}$, an internal diameter of less than $1 \mathrm{~nm}$, and lengths ranging from several hundred nanometers to micrometers. ${ }^{2}$ Figure 1 provides a schematic representation of the structure of imogolite nanofiber. The outer surface of imogolite is composed of $\mathrm{Al}-\mathrm{OH}$ groups; therefore, the outer surface wall can be charged depending on the solution $\mathrm{pH}$. Due to the electrostatic repulsion, the isolated units can form nanofibers under acidic conditions. ${ }^{3}$ Imogolite with a unique tubular nanostructure has been discussed in the field of materials science for application as a membrane, catalyst, or ad-

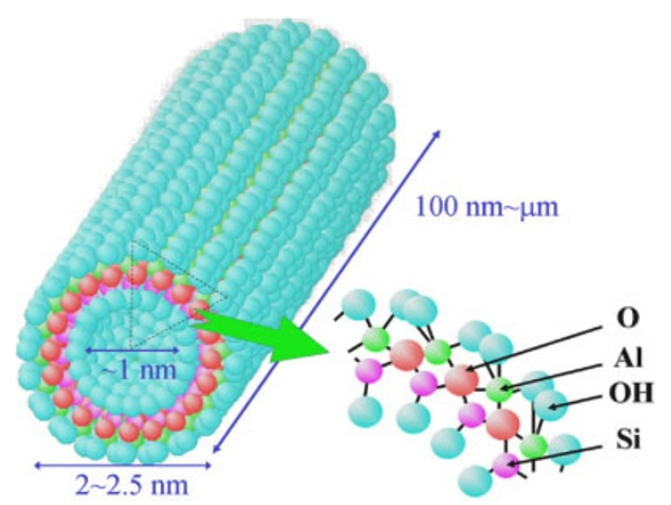

Figure 1. Schematic representation of structure of imogolite nanofiber. sorbent. ${ }^{4-6}$ Furthermore, it has been suggested that a polymer nanocomposite with imogolite could have enhanced the mechanical and thermal properties due to its extremely high aspect ratio and large specific surface area. ${ }^{7,8}$ In the case of the other nanofiber, carbon nanotube $\left(\mathrm{CNT}^{9}\right)$ has been utilized as the reinforcement nanofiller of polymer nanocomposites. The strength and toughness with regard to mechanical, ${ }^{10,11}$ thermal, ${ }^{12,13}$ electric, ${ }^{14}$ and flammability properties $^{15,16}$ of polymers have been improved by the addition of CNTs. Various polymer composites with CNTs have been studied such as poly(methyl methacrylate),${ }^{17}$ polystyrene, ${ }^{18,19}$ polypropylene, ${ }^{15,20,21} \mathrm{ep}$ oxy, ${ }^{16}$ and poly(vinyl alcohol), ${ }^{22,23}$ as matrix polymer. However, CNT cannot be used for transparent polymer materials because CNT is colored due to its conjugated $\pi$-system. In contrast, imogolite has a refractive index that is similar to that of common polymers ${ }^{24}$ making it desirable for applications involving transparent polymer additives.

When preparing a polymer nanocomposite, the effective utilization of nanofiller (nanofibers, nanotubes, nanoparticles, etc.) in nanocomposite applications may depend on their dispersibility into the polymer matrix. ${ }^{25}$ Especially, these nanofibers preferentially aggregate into bundles, where adjacent fibers are hold together by strong interaction. ${ }^{3,26}$ This characteristics makes it difficult to disperse nanofibers into the polymer matrix; therefore, considerable research has been focused on two prominent approaches to solving this problem. One of the approaches is the surface functionalization of nanofiller, while the other is in situ synthesis method of organic or inorganic components.

${ }^{\dagger}$ To whom correspondence should be addressed (Tel: +81-92-642-2721, Fax: +81-92-642-2715, E-mail: takahara@cstf.kyushu-u.ac.jp). 
This review will introduce the composite or hybrid system prepared by some methods using natural and synthesized imogolite nanofiber. Figure 2 shows the schematic illustration of polymer hybrid with imogolite nanofiber prepared in this review by different techniques.

\section{PURIFICATION OF IMOGOLITE GEL}

Raw material of imogolite gel was collected from the pumice bed in Kitakami area, Iwate, Japan. The raw material shows a red-brown color due to contaminants such as metal oxides and metal hydroxides. Details of the purification method for imogolite can be found elsewhere. ${ }^{27}$ Purified imogolite gel was dispersed in a weak acidic solution $(\mathrm{pH}=c a .3 \sim 5)$ by applying a $42 \mathrm{kHz}$ ultrasonic wave for several hours. The dispersed imogolite solution was slightly sticky and turbid. Freeze-drying the suspension of imogolite could give a white powder like cotton. Figure 3 shows the detail of and procedure for imogolite purification,

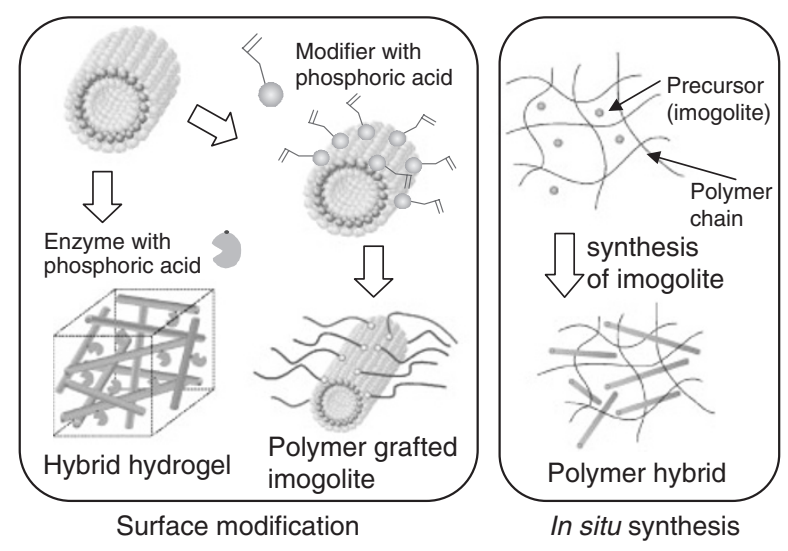

Figure 2. Schematic illustration of polymer hybrid prepared in this review by two different techniques for imogolite nanofiller. which produces the freeze-dried powder and suspension of imogolite was used for preparing hybrid materials is introduced below.

\section{(IMOGOLITE NANOFIBER/PMMA) HYBRID BY POLYMER GRAFTING METHOD}

As described in the introduction, imogolite has outer surface of hydrophilic Al-OH groups and can be dispersed in water under low acidic conditions, it is therefore very difficult to disperse imogolite in hydrophobic polymer matrix. Attempts have previously been made to convert the hydroxylated surface of imogolite to a hydrophobic surface by a surface modification method using organosilanes. ${ }^{28}$ Despite these attempts, the surface properties of imogolite have not successfully been changed by surface treatment with organosilane. ${ }^{29}$ Since alkyl phosphoric acid groups have been used for surface treatment of the Al-sheet, the attempts have been made to modify the surface with alkyl phosphonic acid. ${ }^{30}$ We have reported that modified imogolite nanofiber using alkylphosphonic acid can be dispersed in hydrophobic solvents such as hexane and chloroform, in contrast, while it aggregates in water and ethanol. When we focused on the use of imogolite in polymer composites, it appeared that the surface modification of imogolite could be expected to improve its dispersibility into the hydrophobic polymer matrix. Novel (polymer/imogolite) nanohybrid was prepared by free radical polymerization of methyl methacrylate in the presence of imogolite modified by phosphoric acid ester with a polymerizable methacrylate group, which grafts PMMA chain from the imogolite surface. Improving the dispersibility of imogolite in the polymer matrix is anticipated via the surface PMMA-grafting of imogolite. Figure 4 shows the schematic illustration of preparation of

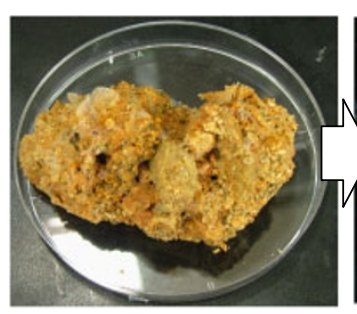

$$
\text { Raw soil including }
$$
imogolite and impurities

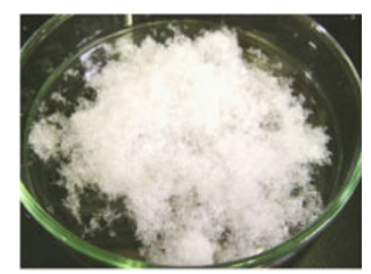

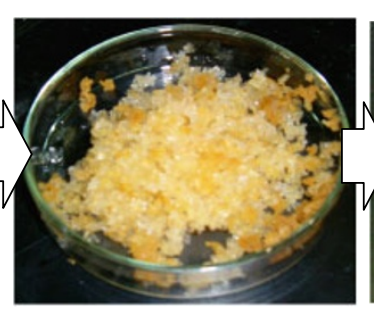

Gel contents removed from raw soil.

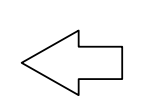

Freeze drying of imogolite suspension

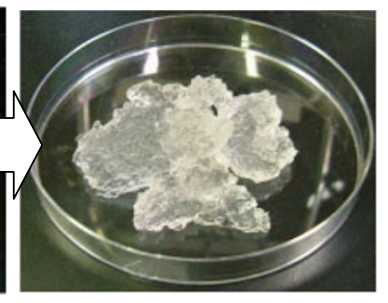

Purified imogolite gel

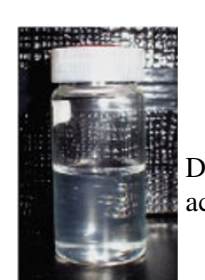

Dispersed imogolite in acidic aqueous solution

Figure 3. The procedure in detail of imogolite purification from raw materials. 


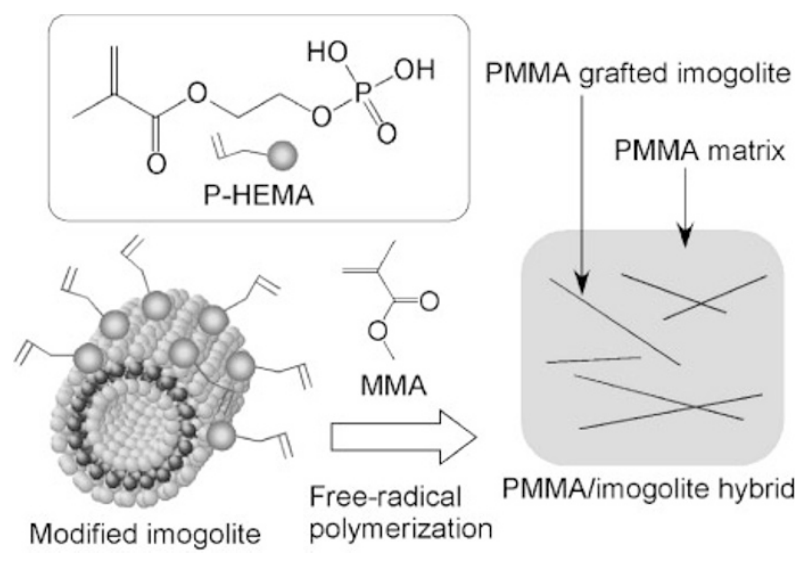

Figure 4. Chemical structure of 2-acidphosphoxyethyl methacrylate (P-HEMA) and illustration of the preparation of polymer hybrid using imogolite modified with P-HEMA. Reprinted with permission from K. Yamamoto et al., Polymer, 46, 12386 (2005). ${ }^{31}$ (C) 2005, Elsevier B.V.

(PMMA/imogolite) nanohybrid. ${ }^{31}$

The freeze-dried imogolite powder purified from natural imogolite gel was used as described above. 2-acidphosphoxyethyl methacrylate (P-HEMA: Figure 4) was used for the surface modifier of imogolite nanofiber. Methyl methacrylate (MMA) was purified by distillation under reduced pressure over calcium hydride. 2,2'-Azo-bis-isobutironitlie (AIBN) was used as an initiator for free radical polymerization.

Imogolite (freeze-dried powder: $46.6 \mathrm{mg}$ ) was dispersed into weak acidic water $(10 \mathrm{~mL}, \mathrm{pH}=5.0)$ using sonication. P-HEMA $(9.32,27.96$, or $46.6 \mathrm{mg})$ was dissolved into water $(20 \mathrm{~mL})$, and the solution was added to the imogolite aqueous suspension under stirring to yield cloudy solution. The weight ratio of imogolite/P-HEMA was 1:0.2, 1:0.6, and 1:1 in the mixed solution. After stirring for $24 \mathrm{~h}$, the solution was centrifuged to collect the white precipitate of imogolite modified with P-HEMA. The precipitate was washed with water three times by centrifugation and decantation to remove the unreacted P-HEMA, and then freeze-dried to give a white powder of imogolite/P-HEMA.

The white powder of imogolite modified with PHEMA (10 mg: the imogolite content was $1 \mathrm{wt} \%$ ) and AIBN (33 mg) as an initiator were mixed with MMA $(1.0 \mathrm{~g})$ in a glass reactor. The molar ratio of the added monomer and initiator was 50:1. The mixture became cloudy due to the suspended imogolite nanofibers. The preparation of PMMA/imogolite hybrid was carried out by heating of the mixture at $343 \mathrm{~K}$ after degassing by freeze-pump-thaw cycle. After heating for $3 \mathrm{~h}$, the obtained solid polymer was dissolved in chloroform and reprecipitated by a large amount of methanol to afford a white powder of PMMA/imogolite hybrid. The yield of PMMA/im-

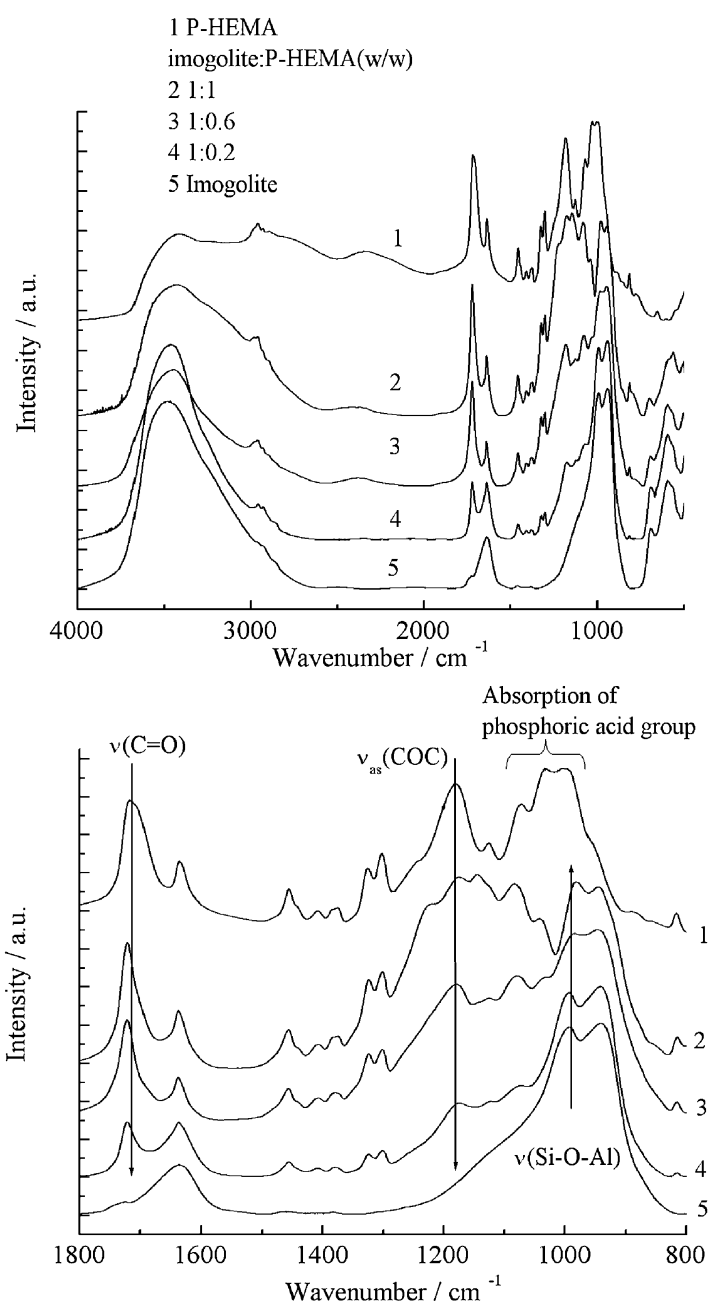

Figure 5. IR spectra of imogolite, P-HEMA, and imogolite adsorbed with P-HEMA at various P-HEMA contents in the full scale (upper) and the region from 1800 to $800 \mathrm{~cm}^{-1}$ (lower). Reprinted with permission from K. Yamamoto et al., Polymer, 46, 12386 (2005). ${ }^{31}$ (C) 2005, Elsevier B.V.

ogolite hybrid was $89.6 \%$. Hybrid films were then prepared by the solvent cast method from PMMA/imogolite solution in order to measure the optical and mechanical properties. The $5 \mathrm{wt} \%$ concentration of PMMA/imogolite chloroform solution was kept in a glass petri dish at room temperature for $12 \mathrm{~h}$. After evaporating the solvent, the film was peeled off from the glass petri dish, and dried in vacuum for $12 \mathrm{~h}$.

P-HEMA can be expected to be adsorbed onto the surface of imogolite due to its phosphoric acid moiety, which can interact with $\mathrm{Al}-\mathrm{OH}$ groups on the imogolite surface. The chemisorption of P-HEMA onto the surface of imogolite was confirmed by infrared (IR) measurement. IR spectroscopic measurement was carried out with a resolution of $0.5 \mathrm{~cm}^{-1}$ at room temperature and collected by averaging 64 scans between 4000 and $500 \mathrm{~cm}^{-1}$. A specimen for IR measurement was prepared under pressure with $\mathrm{KBr}$ powder. Figure 5 shows IR spectra of purified imogolite, P- 
HEMA, and imogolite adsorbed with P-HEMA. The spectrum (Figure 5, No. 5) of imogolite indicated the characteristic absorption of stretching vibration band $(v(\mathrm{Si}-\mathrm{O}-\mathrm{Al}))$ at $995 \mathrm{~cm}^{-1}$ and $935 \mathrm{~cm}^{-1}$, and large broad peak of $v(\mathrm{OH})$ around $3450 \mathrm{~cm}^{-1} .32$ The spectrum of P-HEMA (Figure 5, No. 1) also showed a few characteristic absorption peaks, which are ascribed to the stretching vibration of carbonyl groups $(v(\mathrm{C}=\mathrm{O}))$ at $1714 \mathrm{~cm}^{-1}$, the asymmetric stretching vibration $\left(v_{\text {as }}(\mathrm{COC})\right)$ of the methacryloyloxy group at $1179 \mathrm{~cm}^{-1}$, and several peaks for coupled vibration of $\mathrm{P}-\mathrm{O}$ stretching vibration at 1070,1030 , and 1000 $\mathrm{cm}^{-1} .33,34$ In contrast, P-HEMA chemisorbed imogolite with a weight ratio of 1:0.2 (Figure 5, No. 4), showed adsorption peak at 992 and $935 \mathrm{~cm}^{-1}$, corresponding to the absorption of imogolite, and at 1722 and $1180 \mathrm{~cm}^{-1}$ corresponding to $\left(v(\mathrm{C}=\mathrm{O}), v_{\mathrm{as}}(\mathrm{COC})\right)$ of P-HEMA. These results provide evidence of $\mathrm{P}$ HEMA adsorption onto imogolite surface. Furthermore, the P-HEMA content in the imogolite/P-HEMA system (Figure 5, No. 2 and No. 3) increased with the intensity of absorption peaks at $1080 \mathrm{~cm}^{-1}$ corresponding to the $v_{\mathrm{as}}\left(\mathrm{PO}_{3}{ }^{2-}\right)$ band. Also, the $v_{\mathrm{s}}\left(\mathrm{PO}_{3}{ }^{2-}\right)$ absorption peak generally appears around $980 \mathrm{~cm}^{-1}$ when a phosphoric acid group interacts with the substrate surface. ${ }^{33}$ As a consequence, the absorption around $995 \mathrm{~cm}^{-1}$ suggests that the modified imogolite with P-HEMA broadened and the peak shifted to $987 \mathrm{~cm}^{-1}$ for $1: 0.6$ and $982 \mathrm{~cm}^{-1}$ for $1: 1$, because of the extent of interaction between the phosphoric acid groups of P-HEMA and $\mathrm{Al}-\mathrm{OH}$ groups of imogolite.

The fraction of imogolite and P-HEMA was estimated by thermal gravimetric analysis (TGA) and elemental analysis. TGA measurement was conducted from $323 \mathrm{~K}$ to $1273 \mathrm{~K}$ at heating rate of $10 \mathrm{~K} / \mathrm{min}$. Approximately $1 \mathrm{mg}$ of each sample was placed on a platinum pan. Figure 6 shows the TGA curves of im-

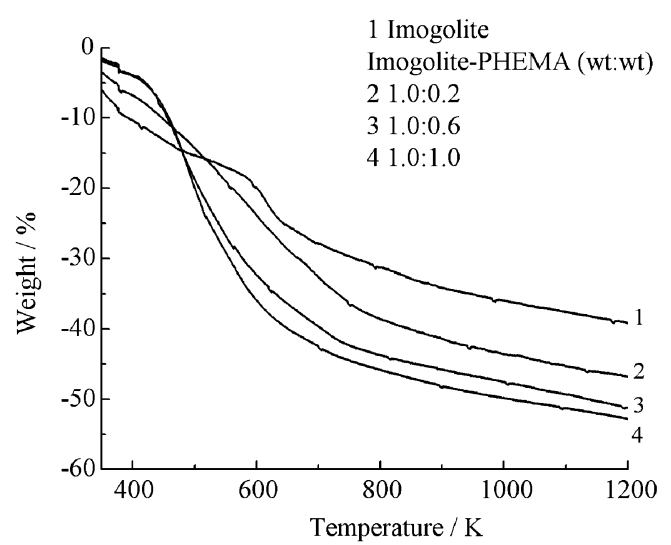

Figure 6. TGA curves of imogolite and imogolite adsorbed with P-HEMA at various P-HEMA contents. Reprinted with permission from K. Yamamoto et al., Polymer, 46, 12386 (2005). ${ }^{31}$ (C) 2005, Elsevier B.V. ogolite and surface modified imogolite by P-HEMA with various weight contents. Two steps of weight loss were observed in the TGA curve of imogolite, which is similar to the results reported by other investigators. ${ }^{1,35}$ These weight losses indicated release of adsorbed water and structural water. On the other hand, the TGA curves of the modified imogolite showed the rapid weight loss from $430 \mathrm{~K}$ in the modified imogolite, including the high P-HEMA contents. This weight loss from $430 \mathrm{~K}$ reflects the desorption and degradation of P-HEMA. The amounts of adsorbed P-HEMA on the surface of imogolite estimated from elemental analysis were $0.15 \mathrm{mg}$ per $1 \mathrm{mg}$ of imogolite (imogolite:P-HEMA = 1:0.2), $0.36 \mathrm{mg}(1: 0.6)$, and $0.51 \mathrm{mg}(1: 1)$, respectively. Furthermore, the coverage of the surface of imogolite with P-HEMA was estimated to be $13.8,33.5$, and $47.5 \%$. The coverage value of surface imogolite was evaluated by the assumption of the complete modification of P-HEMA onto imogolite nanofiber.

Figure 7 shows the transmission electron microscopic (TEM) image of imogolite nanofiber adsorbed with P-HEMA. TEM observations were performed with an acceleration voltage of $100 \mathrm{kV}$ using copper grid covered carbon film. The dispersibility of these nanofibers was found to be similar to the morphology of unmodified imogolite nanofibers dispersed into low acidic water, as the diameter of nanofibers is around several nanometers or over ten nanometers in both cases. The dispersibility of nanofibers also supports the successful surface modification of imogolite with P-HEMA.

The imogolite modified by P-HEMA with a large

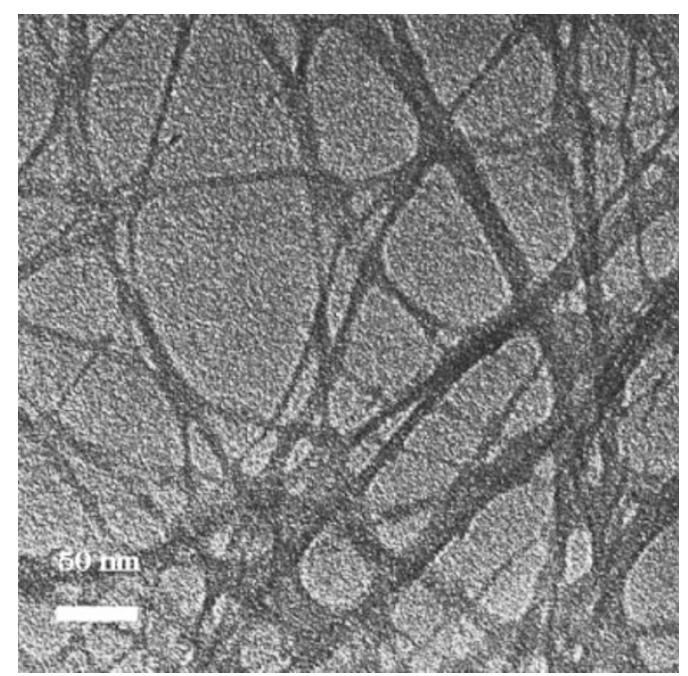

Figure 7. TEM image of surface modified imogolite nanofibers adsorbed with P-HEMA. The sample was prepared from dispersed chloroform solution. Reprinted with permission from K. Yamamoto et al., Polymer, 46, 12386 (2005). ${ }^{31}$ (C) 2005, Elsevier B.V. 
Table I. Molecular weight and polydispersity index of soluble polymer contents in PMMA/imogolite hybrid ${ }^{\mathrm{a}}$

\begin{tabular}{ccccc}
\hline Run No. & $\begin{array}{c}\text { Content of } \\
\text { imogolite }(\mathrm{wt} \%)\end{array}$ & $M_{\mathrm{n}}$ & $M_{\mathrm{w}} / M_{\mathrm{n}}$ & $\begin{array}{c}\text { State of } \\
\text { imogolite }\end{array}$ \\
\hline 1 & 0 & 58800 & 2.50 & - \\
2 & 1.0 & 65100 & 2.55 & Modified \\
3 & 1.0 & 65600 & 2.54 & Unmodified \\
\hline
\end{tabular}

${ }^{\mathrm{a} O n l y}$ soluble part through $0.5 \mu \mathrm{m}$ size filter was measured.

amount of adsorption (imogolite:P-HEMA $=1: 1$ ) was employed for in situ MMA polymerization to prepare the PMMA/imogolite nanohybrid. The polymerization of MMA was confirmed by IR and NMR measurements. The conversion of MMA in this condition was $95-98 \%$, as estimated by NMR measurement. The number average molecular weight $\left(M_{\mathrm{n}}\right)$ and the polydispersity index $\left(M_{\mathrm{w}} / M_{\mathrm{n}}\right)$ for the soluble polymer content were estimated by gel permeation chromatography (GPC) and are summarized in Table I. To confirm the formation of PMMA in the presence of imogolite nanofiber, both modified and unmodified imogolite were used. GPC was carried out at $313 \mathrm{~K}$ with THF as an eluent and using only the soluble part of the polymer hybrid through $0.5 \mu \mathrm{m}$ filter before analysis. GPC results indicated a lesser influence of MMA polymerization in the presence of $1.0 \mathrm{wt} \%$ imogolite. We used primarily the products of PMMA and PMMA/modified imogolite hybrid prepared through in situ polymerization with the aim of characterizing the mechanical and optical properties of hybrid materials. PMMA polymerized without imogolite was utilized for PMMA/imogolite blend film by simple solution blending.

After polymerization of MMA in the presence of the modified imogolite nanofibers, the surface grafting of imogolite nanofibers by PMMA chains was confirmed by IR measurement and the state of dispersion in contrastive solvent. To recover the PMMA-grafted imogolite, the chloroform suspension of polymerized PMMA/imogolite hybrid was centrifuged. Precipitated imogolite powder was rinsed with chloroform a few times to remove free PMMA homopolymers. Figure 8 shows the IR spectra of PMMA, modified imogolite, and unmodified imogolite powder recovered from PMMA/imogolite hybrid chloroform solution. In the spectrum of PMMA, the stretching vibration bands of $\mathrm{CH}_{2}$ and $\mathrm{C}=\mathrm{O}$ at $2996 \mathrm{~cm}^{-1}, 2952$ $\mathrm{cm}^{-1}$, and $1733 \mathrm{~cm}^{-1}$ were clearly observed. The spectrum of the modified imogolite after polymerization showed evidence of PMMA chain attributed to the $\mathrm{CH}_{2}$ and $\mathrm{C}=\mathrm{O}$ absorption peaks at 2996, 2953, and $1727 \mathrm{~cm}^{-1}$ and retained the coupled vibration of the $\mathrm{P}-\mathrm{O}$ stretching vibration at $1080 \mathrm{~cm}^{-1}$. The $\mathrm{C}=\mathrm{O}$ band peak at $1727 \mathrm{~cm}^{-1}$ of the modified imogo-

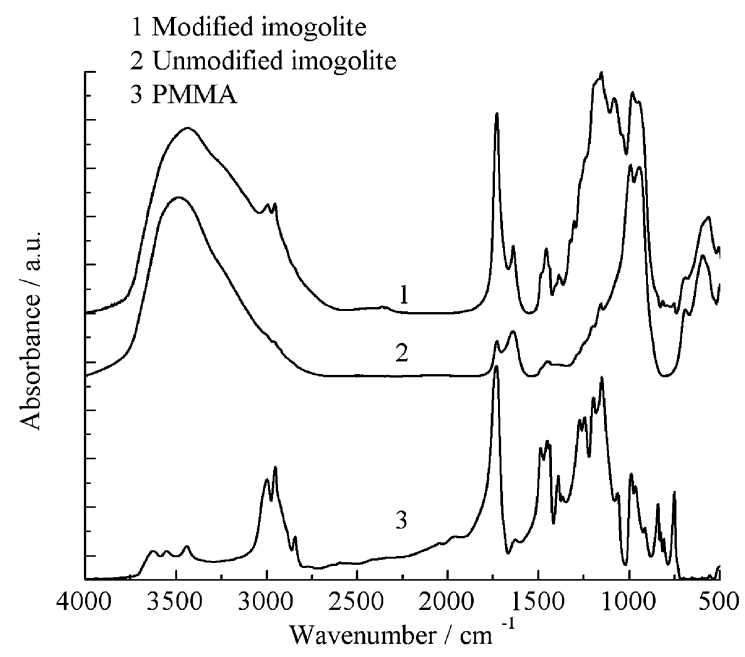

Figure 8. IR spectra of PMMA, modified imogolite, and unmodified imogolite recovered from PMMA/imogolite hybrid chloroform solution. Reprinted with permission from K. Yamamoto et al., Polymer, 46, 12386 (2005). ${ }^{31}$ (C) 2005, Elsevier B.V.

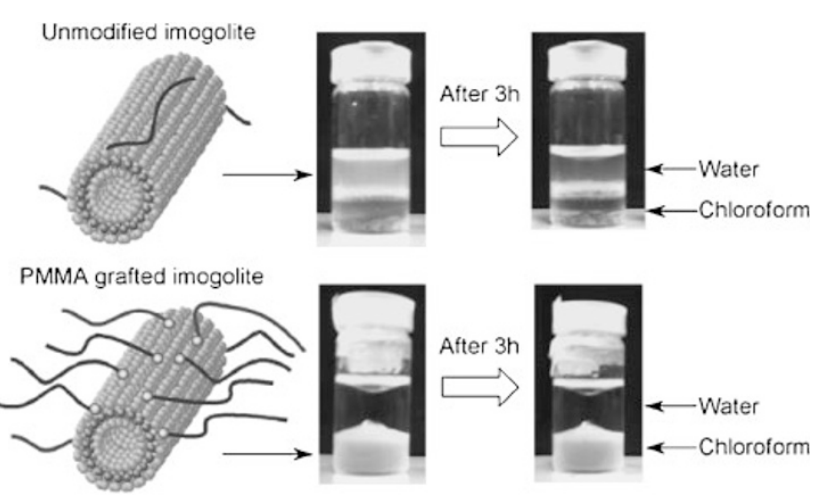

Figure 9. Dispersion state of PMMA grafted imogolite and unmodified one in water/chloroform phase. Reprinted with permission from K. Yamamoto et al., Polymer, 46, 12386 (2005). ${ }^{31}$ (C) 2005, Elsevier B.V.

lite shifted slightly to the lower wavenumber side in comparison with the spectrum of PMMA, due to the difference in the environment between the grafted PMMA chain and the bulk PMMA. These results revealed that MMA can be polymerized and grafted via the methacryloyl group of adsorbed P-HEMA on the surface of imogolite. In addition, the presence of the absorption peak at $3450 \mathrm{~cm}^{-1}$ and the two peaks around $995-935 \mathrm{~cm}^{-1}$ demonstrates the retention of imogolite structure after free radical polymerization process. In contrast, the unmodified imogolite indicated very weak absorption peaks corresponding to the polymer chain. Since unmodified imogolite without reactive methacrylate group cannot be grafted by PMMA, these weak peaks indicated a small amount of physical adsorption of PMMA chain onto the surface of unmodified imogolite.

Figure 9 shows the dispersion states of PMMA- 


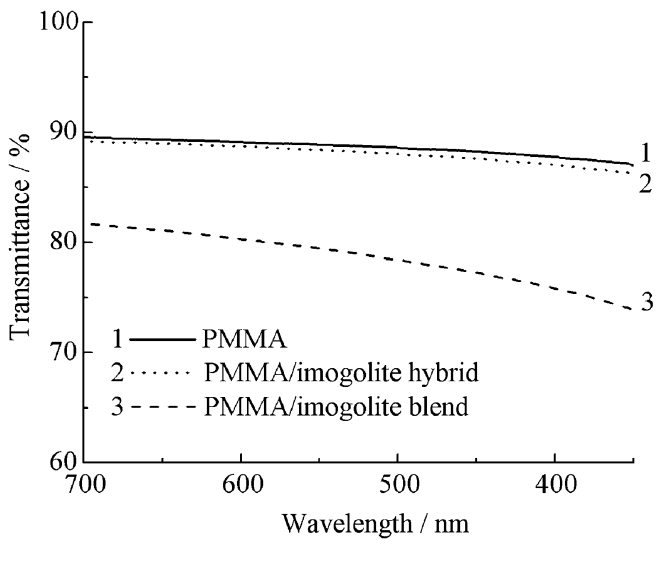

Figure 10. Light transmittance of PMMA, PMMA/imogolite hybrid, and PMMA/imogolite blend films in the visible light region. Imogolite content was $1.0 \mathrm{wt} \%$. Reprinted with permission from K. Yamamoto et al., Polymer, 46, 12386 (2005). ${ }^{31}$ (C) 2005, Elsevier B.V.

grafted imogolite and unmodified imogolite powders. These powders were added to immiscible liquids such as water and chloroform mixed solution and were dispersed by ultrasonic treatment for $10 \mathrm{~min}$. After sonication, the unmodified imogolite did not disperse in the chloroform phase, but did in the aqueous phase. IR measurement revealed the physical adsorption of PMMA chains onto the surface of unmodified imogolite, but unmodified imogolite could not disperse in chloroform because the PMMA chain desorbed from the imogolite surface and dissolved into the chloroform phase. Furthermore, unmodified imogolite was precipitated onto the interface between water and chloroform after $3 \mathrm{~h}$. On the other hand, PMMA-grafted imogolite powder dispersed in the chloroform phase and did not precipitate in the solution even after several days. The stable dispersion of PMMA grafted imogolite was due to the high affinity for chloroform, which is a good solvent for PMMA. IR measurement and the observation of dispersibility in solvent confirmed that PMMA was successfully grafted from surface modified imogolite with P-HEMA.

PMMA is usually used as a transparent material, and it is important to retain the optical properties of PMMA, even after dispersion of reinforcing filler into polymer matrix. The grafted PMMA chains on the imogolite surface can be expected to provide a high affinity between imogolite nanofibers and PMMA matrix. To evaluate the optical properties of PMMA/ imogolite hybrid film, the hybrid film including $1 \mathrm{wt} \%$ surface modified imogolite with P-HEMA was prepared. As a reference, the blend film with same imogolite content was prepared from PMMA and unmodified imogolite mixed solution. Figure 10 shows the transparency of PMMA, PMMA/imogolite hybrid, and PMMA/imogolite blend films by light
Table II. Haze value and transmittance of PMMA, PMMA/ imogolite hybrid, and PMMA/imogolite blend films ${ }^{\mathrm{a}}$

\begin{tabular}{lcc}
\hline \multicolumn{1}{c}{ Sample } & Haze value & Transmittance $/ \%^{\mathrm{b}}$ \\
\hline PMMA & $0.59 \pm 0.11$ & 88.6 \\
PMMA/imogolite (hybrid) & $1.18 \pm 0.07$ & 88.0 \\
PMMA/imogolite (blend) & $3.37 \pm 0.56$ & 78.4 \\
\hline
\end{tabular}

${ }^{a}$ The content of imogolite in polymer matrix was $1.0 \mathrm{wt} \%$. ${ }^{\mathrm{b}}$ Determined by light transmission measurement at $\lambda=500$ nm.

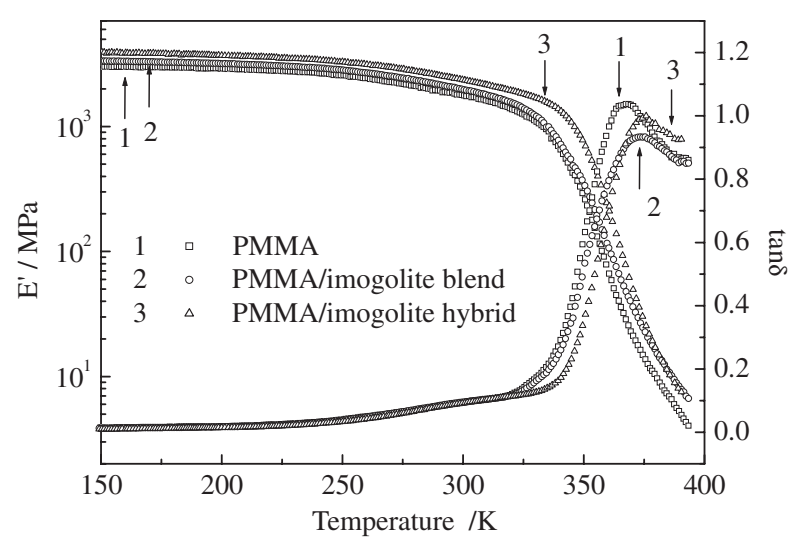

Figure 11. Temperature dependence of dynamic storage modulus and loss tangent at $11 \mathrm{~Hz}$ for PMMA, PMMA/imogolite hybrid, and PMMA/imogolite blend films with $1.0 \mathrm{wt} \%$ imogolite contents. Reprinted with permission from K. Yamamoto et al., Polymer, 46, 12386 (2005). ${ }^{31}$ (C) 2005, Elsevier B.V.

transmission measurement, and Table II indicates the haze value of each film estimated by haze meter. Light transmission was measured with a UV-vis spectrometer at the region of the visible light wavelength from $350 \mathrm{~nm}$ to $700 \mathrm{~nm}$. Haze measurements were carried out using a D65 light source and the values for each sample were averaged after 5 measurements at different film locations. These results show the PMMA/imogolite hybrid film retained the transparency of matrix film, being compared to PMMA/imogolite blend film. This difference in transparency can be attributed to the dispersibility of imogolite nanofibers in the polymer matrix. One of the factors to control the dispersibility is the affinity of the interface between PMMA matrix and the surface of PMMA-grafted imogolite.

Finally, the mechanical properties of PMMA/imogolite hybrid film were investigated by dynamic viscoelasticity measurements and the tensile test. The temperature dependence of dynamic viscoelasticity measurements was carried out using the rectangle shape samples in the tensile mode at $11 \mathrm{~Hz}$ under nitrogen atmosphere with a heating rate of $1 \mathrm{~K} / \mathrm{min}$. The tensile test was carried out at a stretching rate of $1 \mathrm{~mm} / \mathrm{min}$. Figure 11 shows the temperature dependence of the storage modulus $\left(E^{\prime}\right)$ and loss tangent 
Table III. Tensile modulus, strength, and elongation of PMMA, PMMA/imogolite hybrid, and PMMA/imogolite blend films evaluated by tensile test ${ }^{\mathrm{a}}$

\begin{tabular}{lccc}
\hline \multicolumn{1}{c}{ Sample } & Modulus/GPa & Strength/MPa & Elongation/\% \\
\hline PMMA & $1.13 \pm 0.05$ & $27.6 \pm 0.6$ & $38.0 \pm 13.7$ \\
PMMA/imogolite (hybrid) & $1.55 \pm 0.05$ & $38.5 \pm 0.8$ & $21.0 \pm 8.9$ \\
PMMA/imogolite (blend) & $1.20 \pm 0.08$ & $27.7 \pm 1.2$ & $5.0 \pm 1.2$ \\
\hline
\end{tabular}

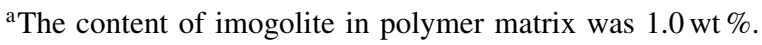

$(\tan \delta)$ for PMMA, PMMA/imogolite hybrid, and PMMA/imogolite blend films. The PMMA/imogolite hybrid or blend film contained $1 \mathrm{wt} \%$ of modified or unmodified imogolite content, respectively. The dynamic storage modulus of PMMA/imogolite hybrid film was approximately 1.5 times higher than that of PMMA film at all temperatures. In addition, the $\alpha_{\mathrm{a}}$ absorption temperature of the hybrid film was higher than that of PMMA film. Table III summarizes the tensile modulus, tensile strength, and elongation of PMMA, PMMA/imogolite hybrid, and PMMA/imogolite blend films evaluated by tensile test. The tensile modulus and the ultimate strength of PMMA/imogolite hybrid were approximately 1.4 times higher than those of PMMA film. On the other hand, the tensile modulus and strength of PMMA/imogolite blend film were similar to those of PMMA film. As the dispersibility of imogolite in the PMMA matrix was improved, the reinforcement effect of imogolite became remarkable in the case of PMMA/imogolite hybrid film. The elongation at the break of PMMA/imogolite hybrid and then blend film was smaller than that of the matrix polymer film, but, the hybrid film clearly showed a greater elongation at the break than the blend film. The reason for the difference in elongation between these films seems due to the lack in the interfacial defect between PMMA-grafted imogolite and matrix PMMA.

\section{(IMOGOLITE NANOFIBER/ENZYME) HYBRID HYDROGEL}

Since imogolite is a natural hydrogel, it can be utilized for the immobilization of biological components. This section introduces the hybrid of imogolite and enzyme having phosphoric acid groups interacting with the imogolite surface ${ }^{36}$ By utilizing the immobilization of the enzyme which has a phosphoric acid group on the nanofiber, it is possible to achieve high loading of enzyme immobilization by immobilizing enzymes with a phosphoric acid group onto the nanofiber. Furthermore, enzyme activity can be expected to be maintained by formation of a hybrid hydrogel immobilized with enzyme because imogolite can form a 3-dimensional network structure in aqueous solution. ${ }^{37}$ The authors introduce herein prepara-
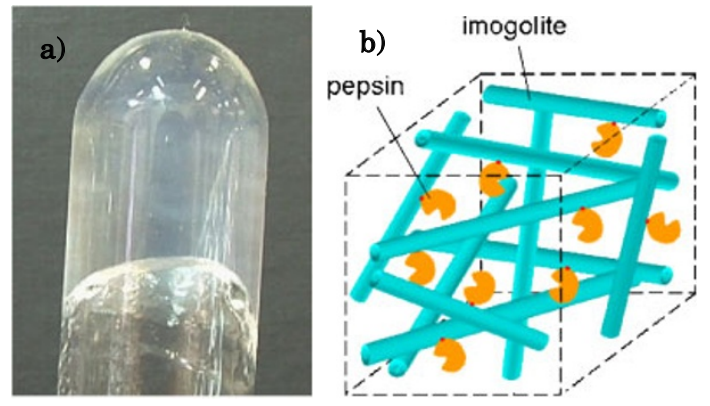

Figure 12. a) Photograph and b) schematic representation of (imogolite/pepsin) hybrid hydrogel. Reprinted with permission from N. Inoue, et al., Chem. Lett., 35, 194 (2006). ${ }^{36}$ (C) 2006, The Chemical Society of Japan.

tion of a hybrid hydrogel via the immobilization of pepsin as a model enzyme with a phosphoric acid group and evaluation of its aggregation structure and enzyme activity.

The (imogolite/pepsin) hybrid hydrogel was prepared by adding $10 \mathrm{~mL}$ of $\mathrm{pH}=3.1$ pepsin solution $(1 \mathrm{mg} / \mathrm{mL})$ to $10 \mathrm{~mL}$ of $\mathrm{pH}=3.1$ imogolite solution $(0.5 \mathrm{mg} / \mathrm{mL})$. The mixture was incubated at $310 \mathrm{~K}$ by shaking at $120 \mathrm{rpm}$ for $4 \mathrm{~h}$. After that, it was centrifuged at $3000 \mathrm{rpm}$ for $15 \mathrm{~min}$ and rinsed 3 times with $\mathrm{pH}=3.1$ acetic acid solution to obtain the hybrid hydrogel. Figure 12 shows a photograph and schematic representation of the structure of the hybrid hydrogel. Pepsin has a phosphoric group at the serine of the 68th residue. ${ }^{38,39}$ The $\mathrm{Al}-\mathrm{OH}$ groups of imogolite are positively charged and dispersed under acidic conditions ( $\mathrm{pH}$ below 5) in aqueous solution by the electrostatic repulsion among them, and pepsin is negatively charged under $\mathrm{pH}=3.1$ because its isoelectric point is 1.0. ${ }^{40}$ This hybrid hydrogel was formed due to the electrostatic interaction between imogolite and pepsin as well as the interaction between $\mathrm{Al}-\mathrm{OH}$ groups of the imogolite surface and the phosphoric group of pepsin. To the best of our knowledge, this is the first report of a hybrid hydrogel prepared via the immobilization of enzyme onto inorganic nanofibers.

The immobilization of pepsin was confirmed by IR measurement using the $\mathrm{KBr}$ method. Figure 13 shows IR spectra of imogolite, pepsin, and hybrid hydrogel immobilized with pepsin. The absorption peaks at 995 and $940 \mathrm{~cm}^{-1}$ can be attributed to the stretch- 


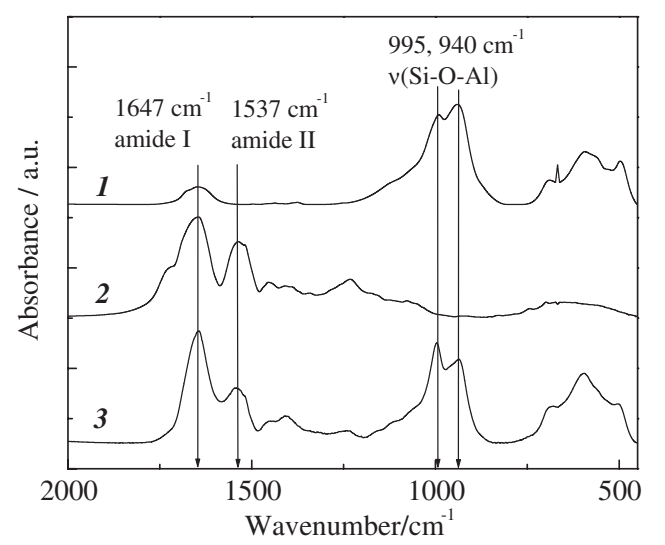

Figure 13. IR spectra of (1) imogolite, (2) pepsin, and (3) hybrid hydrogel immobilized with pepsin. Reprinted with permission from N. Inoue, et al., Chem. Lett., 35, 194 (2006). ${ }^{36}$ (C) 2006, The Chemical Society of Japan.

ing vibration of $\mathrm{Si}-\mathrm{O}-\mathrm{Al}$ in imogolite, and those at 1647 and $1537 \mathrm{~cm}^{-1}$ to amide I and II bands in pepsin, respectively. ${ }^{41}$ The immobilization of pepsin by the interaction between pepsin and imogolite was indicated, since the absorption peaks of pepsin and imogolite were observed simultaneously and the intensity ratio of absorption peaks from imogolite at 995 and $940 \mathrm{~cm}^{-1}$ was changed before and after immobilization. Furthermore, the same absorption peaks from amide I and II bands before and after immobilization suggest that pepsin was not denatured. The amount of immobilized pepsin was estimated by TGA measurement. The sample for TGA was prepared by heating the freeze-dried hybrid hydrogel in toluene at $357 \mathrm{~K}$, which is the azeotropic temperature between $\mathrm{H}_{2} \mathrm{O}$ and toluene mixture, and residual toluene was removed by vacuum drying. The maximum value was approximately $1.8 \mathrm{mg}$ of pepsin per $1 \mathrm{mg}$ of imogolite. Assuming a single-fiber dispersion of imogolite, this maximum value indicates that $c a .71 \%$ of the surface of imogolite is covered with pepsin molecules.

Confocal laser scanning microscopy (CLSM) and field-emission scanning electron microscopy (FESEM) were used to evaluate the dispersion state of pepsin in the hybrid hydrogel and the network structure of hybrid hydrogel. The sample for CLSM observation was prepared with hybrid hydrogel composed of pre labeled imogolite and pepsin. Imogolite and pepsin were labeled with fluorescein 5-isothiocyanate and adenosine 50-triphosphate, Alexa Fluor ${ }^{\circledR} 647$ 20(or-30)-O-( $\mathrm{N}$-(2-aminoethyl)-urethane), and hexa(triethylammonium) salt, respectively. For FE-SEM observation, hybrid hydrogel was dehydrated by freeze-drying and the specimen was prepared by pre coating dehydrated hybrid hydrogel with $\mathrm{OsO}_{4}$. Pepsin was found to be finely dispersed in the hybrid hydrogel, and the fluorescent images of pepsin and imogolite

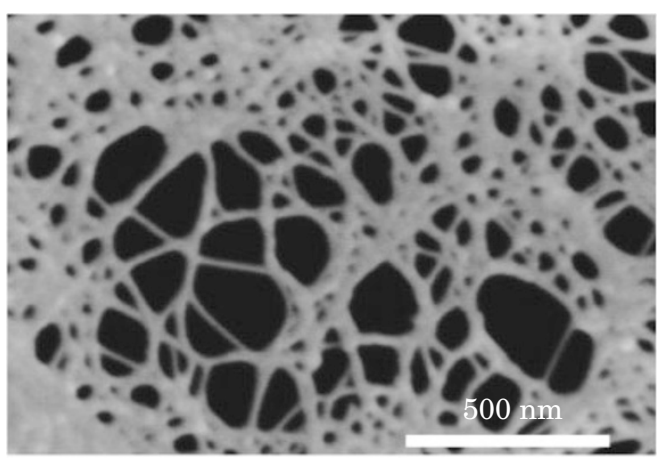

Figure 14. FE-SEM image of the hybrid hydrogel immobilized with pepsin. Reprinted with permission from N. Inoue, et al., Chem. Lett., 35, 194 (2006). ${ }^{36}$ (C) 2006, The Chemical Society of Japan.

showed a similar morphology (figure not shown) due to the immobilization of pepsin onto the imogolite surface. Figure 14 shows the FE-SEM image of the hybrid hydrogel with $99.7 \%$ water content. The 3-dimensional network structure of the hybrid hydrogel composed of imogolite could be directly observed. The average pore size of the hybrid hydrogel in this image was $108 \mathrm{~nm}$.

The enzyme activity of immobilized pepsin in the hybrid hydrogel was evaluated based on hydrolysis of hemoglobin at $\mathrm{pH}=3.1$. Each sample of hybrid hydrogel and free pepsin solution was mixed with $2.5 \mathrm{~mL}$ of $2.5 \mathrm{wt} \%$ hemoglobin solution and incubated at $310 \mathrm{~K}$ for $10 \mathrm{~min}$. Next, $5 \mathrm{~mL}$ of $5 \mathrm{wt} \%$ trichloroacetic acid was added to the mixture and the reaction mixture was incubated at $310 \mathrm{~K}$ for $1 \mathrm{~h}$. After centrifugation and filtration, the filtrate products were measured by UV-vis spectroscopy to estimate the reaction rate, $\Delta \mathrm{A}_{280} / \mathrm{min} . \Delta \mathrm{A}_{280} / \mathrm{min}$ shows the change in absorbance at $280 \mathrm{~nm} . \Delta \mathrm{A}_{280} / \mathrm{min}$ of free pepsin was 0.183 , and that of immobilized pepsin in the hybrid hydrogel was 0.048 . Therefore, immobilized pepsin in the hybrid hydrogel retained $c a .26 \%$ of its enzyme activity compared with free pepsin in aqueous solution. The enzyme activity of immobilized pepsin was apparently decreased. Similar behavior has been observed for the enzyme immobilized at the inner surface of halloysite. ${ }^{42}$ This decrease could be ascribed to the slow diffusion of substrate into the network structure of the hybrid hydrogel shown in Figure 14 as well as to inhibition of the diffusion of substrate to the active site of immobilized pepsin due to the steric hindrance of the imogolite network. In the case of pepsin immobilized in the hybrid hydrogel, it can be easily recovered from the reaction system and can repeatedly react with the substrate. The change in enzyme activity was investigated in the repeated reaction. Figure 15 shows the change in enzyme activity of immobilized pepsin in the hybrid hydrogel. In fact, 


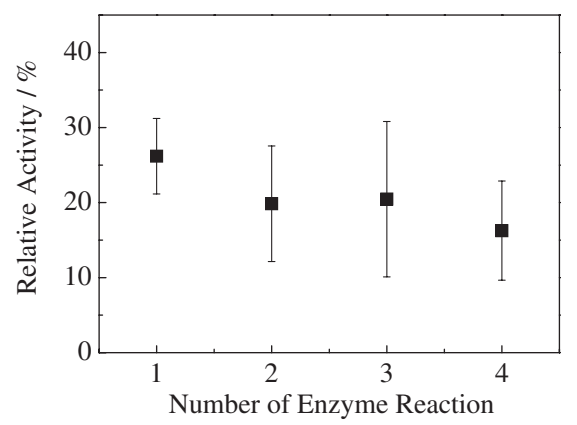

Figure 15. The enzyme activity change of immobilized pepsin during the repeated reaction at $410 \mathrm{~K}$. Reprinted with permission from N. Inoue, et al., Chem. Lett., 35, 194 (2006). ${ }^{36}$ (C) 2006, The Chemical Society of Japan.

the enzyme activity of immobilized pepsin was retained after four reactions, with a slight decrease in activity as the number of reactions increased.

\section{(IMOGOLITE NANOFIBER/PVA) HYBRID PREPARED BY IN SITU METHODS}

Imogolite also has the advantage of being able to be prepared artificially like a CNT ${ }^{43}$ making it potentially useful in various commercial applications. A synthetic pathway of imogolite was first described in 1977 from dilute solutions of aluminium chloride and monomeric orthosilicic acid, ${ }^{44}$ and several investigations concerning synthetic methods for imogolite have been reported. ${ }^{45,46}$ However, the preparation of a polymer-nanofiber hybrid utilizing in situ synthesized imogolite has not been achieved thus far. The authors introduce here the synthetic method for an aluminosilicate nanofiber in polymer solution toward the preparation of a nanohybrid, and characterization of the imogolite/polymer hybrid prepared by in situ synthesis. ${ }^{47}$

Imogolite was synthesized essentially by the method described by Farmer et al. ${ }^{44}$ An aqueous solution of aluminum chloride $\left[\mathrm{AlCl}_{3} \cdot 6 \mathrm{H}_{2} \mathrm{O}\right]$ was mixed with an aqueous solution of tetraethoxysilane $\left[\mathrm{Si}(\mathrm{OEt})_{4}\right]$. The final concentration of the solution was 2.4 mmol L ${ }^{-1}$ with respect to $\mathrm{Al}$ and $1.4 \mathrm{mmol} \mathrm{L}^{-1}$ for $\mathrm{Si}$. The solution was stirred for an hour in order to hydrolyze tetraethoxysilane. Aqueous sodium hydroxide $\left(0.1 \mathrm{~mol} \mathrm{~L}^{-1}\right)$ was then slowly added until the aqueous solution reached $\mathrm{pH} 5$, with a slightly cloudy appearance. Furthermore, the solution was reacidified by the addition of $1 \mathrm{~mL}$ of hydrochloric acid $\left(1 \mathrm{~mol} \mathrm{~L}^{-1}\right)$ and $2 \mathrm{~mL}$ of acetic acid $\left(1 \mathrm{~mol} \mathrm{~L}^{-1}\right)$ per liter of solution. The solution was then stirred at $369 \mathrm{~K}$ for various periods. After being cooled to room temperature, the suspended material was gelated by sodium chloride solution $\left(8.6 \mathrm{mmol} \mathrm{L}^{-1}\right)$ and rinsed with distilled water using a $100 \mathrm{~nm}$ Millipore filter. The rinsed imogo-

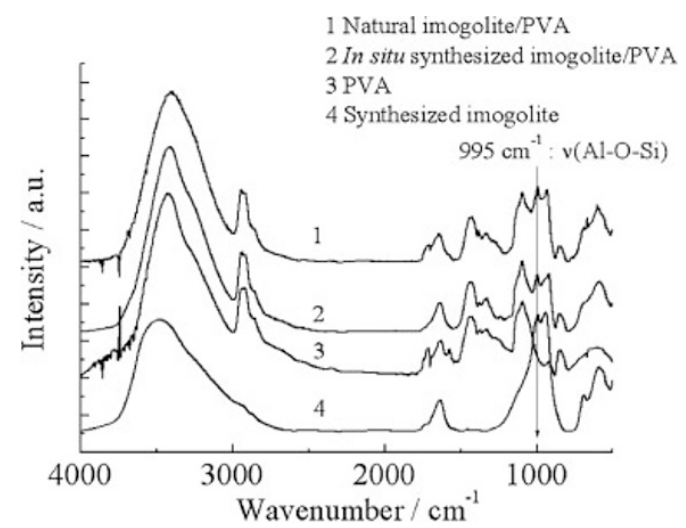

Figure 16. IR spectra of natural imogolite/PVA blend, in situ synthesized imogolite/PVA, PVA, synthesized imogolite, respectively. Reprinted with permission from K. Yamamoto, et al., Soft Matter, 1, 372 (2005). ${ }^{47}$ (C) 2005, Royal Society of Chemistry.

lite gel in the low acidic aqueous solution was redispersed by sonication. The white solid obtained by freeze-drying of the dispersed solution was light and fluffy, similar to natural imogolite. The yield of the freeze-dried products was $67.3 \%$.

The freeze-dried synthetic imogolite sample was characterized by IR measurement with $\mathrm{KBr}$ method. Figure 16 (Curve 4) shows the IR spectrum of synthesized imogolite reacted for $96 \mathrm{~h}$. This spectrum shows two sharp absorptions at 995 and $935 \mathrm{~cm}^{-1}$, which were assigned to the $\mathrm{Si}-\mathrm{O}-\mathrm{Al}$ stretching vibration, and a large absorption at $3440 \mathrm{~cm}^{-1}$ corresponding to the $\mathrm{OH}$ stretching vibration. The IR spectra in this region were not sufficiently distinctive to allow for the presence of other aluminosilicates such as allophane (spherical structure). A previous paper regarding the synthesis of imogolite ${ }^{48}$ has indicated that the appropriate reaction time for the formation of imogolite is 4-5 days. Actually, the IR spectra of synthesized imogolite heated for $12-72 \mathrm{~h}$ showed adsorption peaks attributed to the by products, because of the remaining imogolite precursor (not shown). Consequently, the reaction time of the in situ synthesis in the polymer solution was set at $96 \mathrm{~h}$.

The polymer nanohybrid was prepared by in situ synthesis of imogolite in the presence of poly (vinyl alcohol): PVA in solution. PVA having hydroxyl groups can be expected to interaction with the surface of imogolite. PVA with a degree of polymerization of 630 was used. The dilute $\mathrm{Al}$ and Si solution adjusted $\mathrm{pH}$ was mixed with PVA aqueous solution and stirred at $369 \mathrm{~K}$ for $96 \mathrm{~h}$. The mixed solution was prepared with different mass-fraction ratios of 1:1, 1:5, 1:10, $1 ; 20$, and 1:50, respectively. After cooling, the mixed solution of imogolite and PVA was reprecipitated with ethanol, and the precipitate was filtered using a $450 \mathrm{~nm}$ Millipore filter and then rinsed with water 
and ethanol. The white product of in situ synthesized imogolite/PVA hybrid was then obtained. Furthermore, the cast film was prepared from in situ synthesized imogolite/PVA solution in order to measure the optical and mechanical properties of the films. The hybrid films used in this method were prepared by the cast method from imogolite/PVA solution. The concentration of imogolite/PVA aqueous solution was $5 \mathrm{wt} \%$. This solution was kept in a glass petri dish hydrophobical surface-treated at $323 \mathrm{~K}$ for $12 \mathrm{~h}$. After drying, the film was peeled from the glass petri dish and dried in vacuum for $12 \mathrm{~h}$. As reference samples, the PVA homo polymer and freeze-dried imogolite/ PVA blend films were also prepared in the same way. The thickness of these cast films were $c a$. $100 \mu \mathrm{m}$.

To characterize the imogolite hybrid by the in situ synthetic method, IR measurement was carried out. Figure 16 (Curves 1-3) shows the IR spectra of PVA and the imogolite/PVA hybrid samples prepared by two different methods. One was prepared by the in situ method and the other by the blending of PVA powder and freeze-dried natural imogolite. The weight ratio of the imogolite to PVA was 1:1 for each sample. The characteristic absorption peaks of PVA were appeared at $2945 \mathrm{~cm}^{-1}: v_{\mathrm{a}}\left(\mathrm{CH}_{2}\right), 2915 \mathrm{~cm}^{-1}$ : $v_{\mathrm{s}}\left(\mathrm{CH}_{2}\right), 1430 \mathrm{~cm}^{-1}: \delta\left(\mathrm{CH}_{2}\right)$, and $1095 \mathrm{~cm}^{-1}: v(\mathrm{C}-$ O). ${ }^{49}$ In addition, the IR spectra of the hybrid with imogolite showed two sharp peaks corresponding to the $\mathrm{Si}-\mathrm{O}-\mathrm{Al}$ stretching vibration, which were the same as those shown by the synthesized imogolite. (Curve 4) The IR spectra of the natural imogolite/PVA and synthetic imogolite/PVA hybrid materials are quite similar to that of the PVA powder, except for the characteristic imogolite absorptions at 995 and $930 \mathrm{~cm}^{-1}$. These results suggest that imogolite was successfully formed in the polymer solution.

The molecular aggregation state of synthesized imogolite/PVA hybrid was confirmed by wide angle $\mathrm{X}$-ray diffraction (WAXD) measurements. WAXD measurement was carried out at the BL02B2 beam line of SPring-8 using white powder products packed in a quartz glass capillary. WAXD used incident Xrays with a wavelength $\lambda$ of $0.10 \mathrm{~nm}$. Figure 17 shows WAXD profiles of natural and synthetic imogolite and the imogolite/PVA hybrid. The imogolite:PVA weight ratio was $1: 1$ for the hybrid. Scattering vector $q\left[\mathrm{~nm}^{-1}\right]$ is defined as $q=(4 \pi / \lambda) \sin \theta$, where $\lambda$ and $\theta$ are the wavelengths of the X-ray and scattering angle, respectively. The d-spacing was calculated by $\mathrm{d}[\mathrm{nm}]=2 \pi / q$. The WAXD pattern of imogolite consists of a number of broad reflections. The reflections at $1.83-1.36$ and $0.79 \mathrm{~nm}$ for natural imogolite, ${ }^{2}$ and at $2.30-1.50$ and $0.95 \mathrm{~nm}$ for synthetic imogolite, ${ }^{48}$ originated from the planes of hexagonally packed

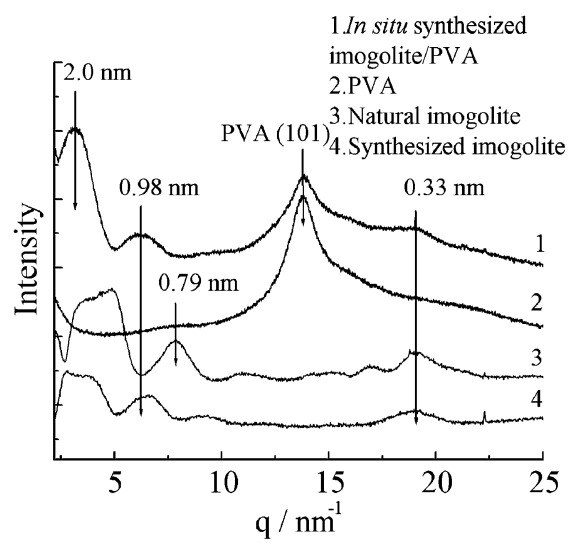

Figure 17. WAXD profiles of natural and synthesized imogolite, PVA and in situ synthesized imogolite/PVA, respectively. Reprinted with permission from K. Yamamoto, et al., Soft Matter, 1, 372 (2005). ${ }^{47}$ C 2005, Royal Society of Chemistry.

nanotube and the scattering of individual nanotubes. Similar diffractions corresponding to the hexagonally packed nanotube have also been observed for a single wall carbon nanotube.$^{50}$ In addition, the PVA crystalline diffraction corresponding to (101) was observed at $0.45 \mathrm{~nm}$. The diffraction peaks for the synthetic imogolite was observed at a lower $q$ value than that for natural imogolite, indicating that the diameter of the synthetic imogolite is slightly larger than that of the natural imogolite. ${ }^{51}$ In the imogolite/PVA hybrid system, the characteristic reflections at 2.0, 0.98, 0.33 and PVA's peak showed the presence of imogolite nanofiber and PVA. The absence of diffraction peaks from by-products suggests that imogolite can be in situ synthesized in PVA aqueous solution.

To observe the morphology of in situ synthesized imogolite in the polymer matrix, the cyclic contact mode atomic force microscopy (AFM) was carried out. The sample for AFM observation was prepared by the spin-coating of a $1 \%$ dispersed solution of imogolite/PVA hybrid at $3000 \mathrm{rpm}$ for $1 \mathrm{~min}$ on a silicon wafer, and the obtained film was then vacuum-dried for $12 \mathrm{~h}$. The AFM observations were carried out at room temperature using a $\mathrm{Si}_{3} \mathrm{~N}_{4}$ rectangular cantilever with a spring constant of $15 \mathrm{~N} \mathrm{~m}^{-1}$, and the resonant frequency of the cantilever was around $160 \mathrm{kHz}$. The setpoint amplitude was $-30 \%$. Figure 18 shows the cyclic contact mode AFM images of the in situ synthesized imogolite/PVA hybrid prepared with various weight ratios of the imogolite/PVA, in a range from 1:1 to 1:50. The brighter areas in the cyclic contact mode AFM image correspond to the higher height region. The AFM images, except for the weight ratio of 1:50 for imogolite/PVA, showed the fiber morphology. This morphology indicates formation of the bundle of imogolite nanofiber. The average length of the synthesized imogolite fiber observed for the films 

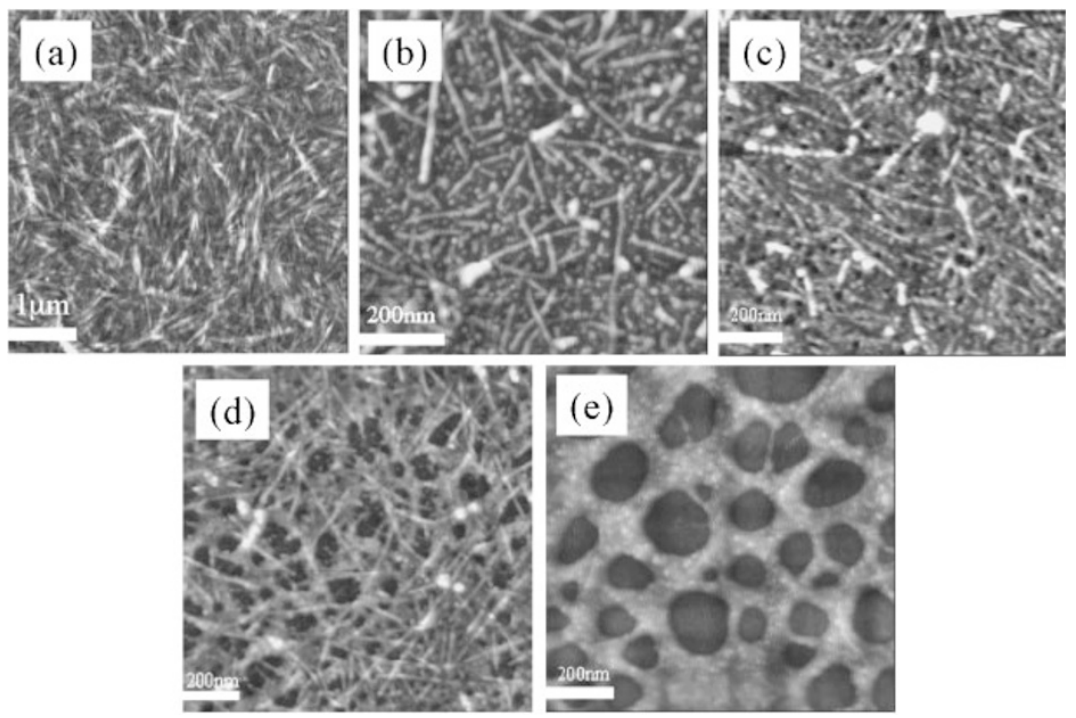

Figure 18. Cyclic contact mode AFM height images of in situ synthesized imogolite/PVA hybrid. Imogolite:PVA (w/w) = (a) 1:1, (b) 1:5, (c) 1:10, (d) 1:20 and (e) 1:50. Reprinted with permission from K. Yamamoto, et al., Soft Matter, 1, 372 (2005). ${ }^{47}$ C 2005, Royal Society of Chemistry.

prepared by the in situ method was several hundred nanometers. This value is smaller than that of typical natural and synthesized imogolite nanofibers. Furthermore, the AFM image of the imogolite/PVA weight ratio of 1:50 (Figure 18e) showed no evidence of imogolite fiber formation. The reason for the inhibition of the formation of the imogolite structure in the PVA matrix is the influence of PVA concentration in the solution. Previous papers have indicated that the important factors governing the formation of imogolite are the $\mathrm{pH}, \mathrm{OH} / \mathrm{Al}, \mathrm{Si} / \mathrm{Al}$ molar ratio, temperature, and additives in the solution. ${ }^{48,52}$ In particular, additives such as organic ligands, which can interact with the aluminum ion, play a decisive role in the formation and nature of short-range ordered aluminosilicate. $^{52}$ The length of the imogolite nanofibers estimated from the AFM images were $689 \pm 47 \mathrm{~nm}$ (imogolite:PVA = 1:1), $271 \pm 21 \mathrm{~nm}(1: 5), 224 \pm 18$ $\mathrm{nm}(1: 10)$, and $178 \pm 9.3 \mathrm{~nm}(1: 20)$, respectively. In contrast, the length of natural imogolite nanofiber was several micrometers, as reported. ${ }^{52}$ These results obtained from the AFM images have revealed that the growth of imogolite nanofibers in the axial direction might be impeded by the presence of PVA due to the interaction between imogolite and PVA. This intermolecular interaction was maintained by the formation of lyotropic mesophase in an imogolite and PVA mixed system. ${ }^{7}$ These results suggest that the higher PVA concentration inhibited the formation of the synthetic imogolite nanofiber. It therefore seems that there is a critical concentration of PVA for the formation of synthesized imogolite.

Optical properties of hybrid films were measured by light transmission and haze value measurements.

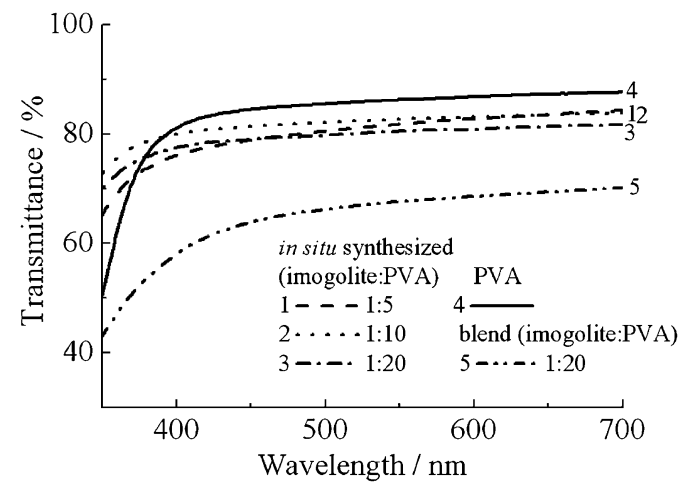

Figure 19. Light transmittance of in situ synthesized imogolite/PVA hybrid, imogolite/PVA blend, and PVA films. The magnitude of transmittance was corrected by the film thickness. Reprinted with permission from K. Yamamoto, et al., Soft Matter, 1, 372 (2005). ${ }^{47}$ C 2005 , Royal Society of Chemistry.

Figure 19 shows the light transmittance through the imogolite/PVA and PVA films. Two kinds of imogolite/PVA films prepared by different procedures were used for the measurement. One was prepared by the in situ method with various weight ratios of imogolite/ PVA, and the other by the blending of PVA and freeze-dried imogolite powder. ${ }^{8}$ Imogolite/PVA hybrid film from the in situ method was optically transparent, and thus comparable to imogolite/PVA blend film with the same quantity of freeze-dried imogolite powder at a high fraction of imogolite. It appears to be difficult to redisperse the freeze-dried imogolite powder, since imogolite fibers aggregate during the process of air-drying or freeze-drying. However, imogolite formed via in situ synthesis in a polymer solution exhibited fine dispersion because adsorbed PVA chains on imogolite nanofibers during the synthetic process 
Table IV. Haze value of in situ synthesized imogolite/PVA hybrid, imogolite/PVA blend and PVA films

\begin{tabular}{lc}
\hline Sample(weight raito) & Haze value/\% \\
\hline PVA & $1.59 \pm 0.19$ \\
Imogolite:PVA 1:20 & $1.00 \pm 0.08$ \\
Imogolite:PVA 1:10 & $0.57 \pm 0.02$ \\
Imogolite:PVA 1:5 & $2.55 \pm 0.08$ \\
Imogolite:PVA 1:20 & $29.94 \pm 3.60$ \\
\hline
\end{tabular}

${ }^{\mathrm{a} B}$ Blend film.

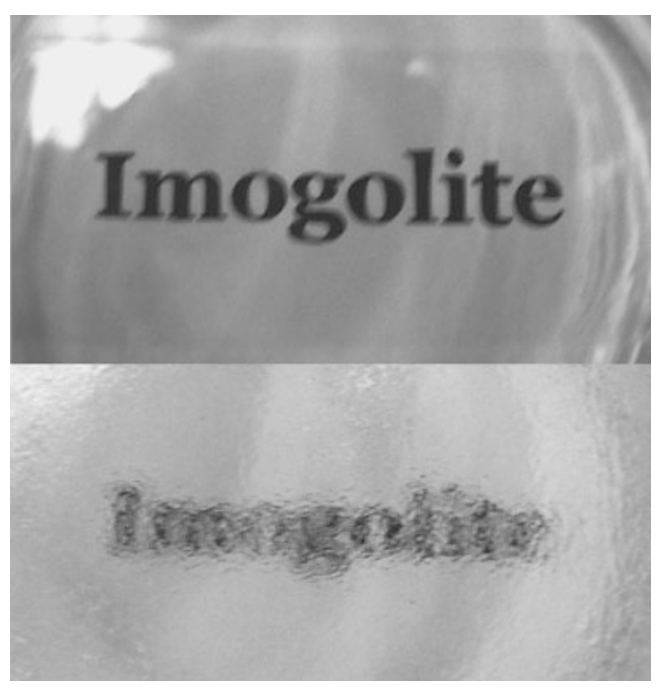

Figure 20. Transparency of in situ hybrid (upper) and blend (lower) films with imogolite:PVA $=1: 20$. The thickness of films is $c a$. $100 \mu \mathrm{m}$ Reprinted with permission from K. Yamamoto, et al., Soft Matter, 1, 372 (2005). ${ }^{47}$ (C) 2005, Royal Society of Chemistry.

inhibited their aggregation. In addition, the PVA hybrid film that contained large amounts of imogolite, up to a weight ratio of 1:5 (imogolite/PVA), could maintain high optical transparency, not only because of the dispersibility of synthetic imogolite in the PVA matrix, but also because of the decrease in the crystallinity and crystallite size of PVA through the strong interaction between imogolite and PVA.

Table IV summarizes the haze value of imogolite/ PVA hybrid films and Figure 20 shows the transparency of in situ hybrid and blend films with the same imogolite contents, which was imogolite:PVA = 1:20. The haze value of the synthesized imogolite/ PVA hybrid and PVA film was low; in contrast, that of the imogolite/PVA blend film was high. The high haze value means that there was a scattering of incident light that passed through the imogolite/PVA blend film due to the presence of aggregated imogolite nanofibers in the polymer matrix. Light transmittance and haze measurements revealed that synthetic imogolite nanofibers prepared by in situ synthesis were finely dispersed in the PVA matrix compared with

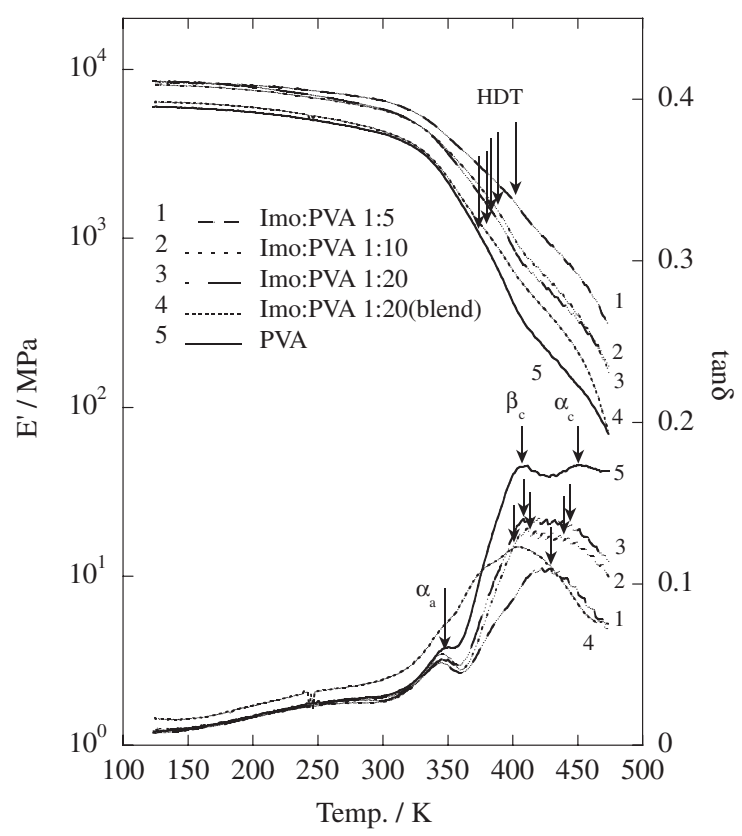

Figure 21. Temperature dependence of storage modulus and loss tangent plots of in situ synthesized imogolite/PVA hybrid, imogolite/PVA blend and PVA films. Reprinted with permission from K. Yamamoto, et al., Soft Matter, 1, 372 (2005). ${ }^{47}$ (C) 2005, Royal Society of Chemistry.

Table V. Room temperature modulus and heat distortion temperature of in situ synthesized imogolite-PVA hybrid, imogolite-PVA blend and PVA films estimated from dynamic viscoelasticity measurement

\begin{tabular}{lcc}
\hline \multicolumn{1}{c}{ Sample } & $E^{\prime} / \mathrm{GPa}^{\mathrm{b}}$ & $\mathrm{HDT} / \mathrm{K}$ \\
\hline PVA & 4.2 & 374 \\
Imogolite:PVA 1:20 & 5.8 & 383 \\
Imogolite:PVA 1:10 & 5.8 & 388 \\
Imogolite:PVA 1:5 & 6.6 & 402 \\
Imogolite:PVA 1:20 & 4.3 & 379 \\
\hline
\end{tabular}

${ }^{\mathrm{a} B}$ Blend film. ${ }^{\mathrm{b}}$ Evaluated at $298 \mathrm{~K}$.

the film prepared by the simple blending of freezedried imogolite and PVA.

The temperature dependence of dynamic viscoelasticity was measured for each sample in order to estimate the mechanical properties of in situ synthesized imogolite/PVA hybrid film. The temperature rage of dynamic viscoelasticity measurement was from $123 \mathrm{~K}$ to $473 \mathrm{~K}$. The upper portion of Figure 21 shows the temperature dependence of the dynamic storage modulus, $E^{\prime}$, of PVA, imogolite/PVA hybrid, and blend films. Table $\mathrm{V}$ summarizes the modulus at room temperature and the heat distortion temperature (HDT) of hybrid and blend films. The HDT value from the dynamic viscoelasticity measurement, which has been proposed by DeVries et al.,$^{53}$ was used. HDT values can be estimated within a sample set from storage modulus data by determining the temperature 


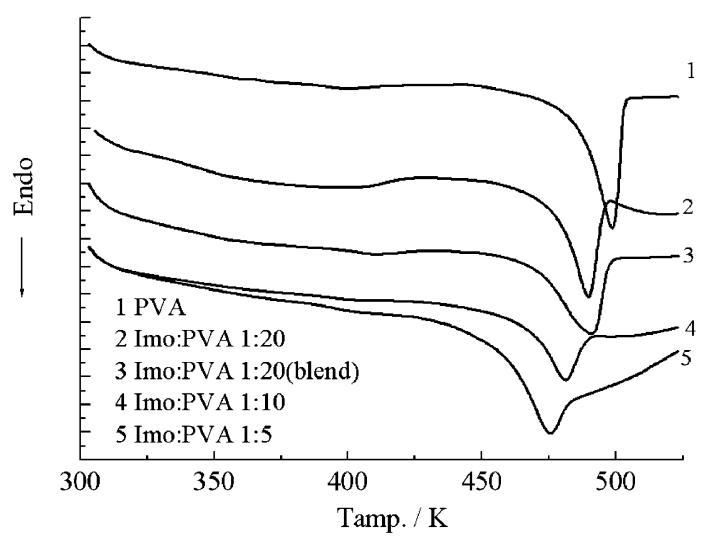

Figure 22. DSC curves of in situ synthesized imogolite/PVA hybrid, imogolite/PVA blend and PVA films. Reprinted with permission from K. Yamamoto, et al., Soft Matter, 1, 372 (2005). ${ }^{47}$ (C) 2005, Royal Society of Chemistry.

at which the storage modulus drops to $25 \%$ of its room temperature value. The downward arrows in Figure 21 indicate the HDT temperature of prepared films. $E^{\prime}$ at room temperature and HDT of in situ synthesized imogolite/PVA hybrid films were found to be higher than that of the PVA film. Furthermore, $E^{\prime}$ and HDT values increased with imogolite content in the polymer matrix. In contrast, no change in $E^{\prime}$ curves between the imogolite/PVA blend film and the PVA film could be observed. The lower portion of Figure 21 shows the temperature dependence of the mechanical loss tangent, $\tan \delta$, of imogolite/PVA hybrid films. Compared with the PVA film, changes in the $\beta_{\mathrm{c}}$ and $\alpha_{\mathrm{c}}$ absorption peaks of in situ imogolite/PVA hybrid films and imogolite/PVA blend film were observed. Both the $\alpha_{\mathrm{c}}$ and $\beta_{\mathrm{c}}$ peaks can be attributed to motions within the crystalline phase of PVA, with the $\alpha_{\mathrm{c}}$ peak being assigned to translational modes of chain segments along the chain axis. ${ }^{54}$ In contrast, the $\beta_{\mathrm{c}}$ peak can be ascribed to an anharmonic twisting vibration around the chain axis. We therefore attribute this change to the change in the molecular aggregation state in crystalline phase of PVA. ${ }^{54}$ The change in crystalline aggregation states was also observed as a change in crystallinity.

Figure 22 shows the DSC curves of PVA and imogolite/PVA hybrid films. DSC was performed under nitrogen gas flow $\left(50 \mathrm{~mL} \mathrm{~min}^{-1}\right)$, from $313 \mathrm{~K}$ to $523 \mathrm{~K}$, at a heating rate of $10 \mathrm{~K} \mathrm{~min}^{-1}$. As shown in Figure 22, DSC curves revealed the decrease in the heat of fusion and the melting point of the PVA crystal in the hybrid film. Table VI summarizes the melting point and crystallinity, calculated from the experimentally obtained heat of fusion, which was estimated from the literature value of pure PVA crystal as a standard. ${ }^{55}$ The magnitude of the heat of fusion of PVA ideal crystal was reported as $156 \mathrm{Jg}^{-1}$. The
Table VI. Crystallinity and melting temperature of PVA calculated from heat of fusion of in situ synthesized imogolite-PVA hybrid, imogolite-PVA blend, and PVA films

\begin{tabular}{lcc}
\hline \multicolumn{1}{c}{ Sample } & Crystallinity $/ \%$ & $T_{\mathrm{m}} / \mathrm{K}$ \\
\hline PVA & $50.9 \pm 5.8$ & $487.4 \pm 0.3$ \\
Imogolite:PVA 1:20 & $32.2 \pm 3.1$ & $476.9 \pm 1.3$ \\
Imogolite:PVA 1:10 & $27.8 \pm 1.8$ & $470.9 \pm 1.4$ \\
Imogolite:PVA 1:5 & $23.2 \pm 1.8$ & $467.2 \pm 2.3$ \\
Imogolite:PVA 1:20 & $33.3 \pm 6.8$ & $471.2 \pm 8.4$ \\
\hline
\end{tabular}

${ }^{\mathrm{a} B l e n d}$ film.

crystallinity was evaluated under consideration of the mass fraction of PVA in the hybrids. A decrease in PVA crystallinity was observed in the imogolite/ PVA hybrid film compared with the PVA film. Generally, the lower the crystallinity of polymer materials, the higher the intensity of $\alpha_{\mathrm{a}}$-absorption in $\tan \delta$ curves $\left(\alpha_{\mathrm{a}}\right.$-absorption was assigned to micro-Brownian motions of long chain segments in the amorphous regions of the polymer) ${ }^{54}$ On the other hand, even though the PVA crystallinity of the in situ imogolite-PVA hybrid film decreased, the $\alpha_{\mathrm{a}}$-absorption of hybrid films was observed as being similar to that of PVA film (Figure 21). The reason for this behavior is thought to be the growth of unstable PVA crystals that do not contribute to the $\alpha_{\mathrm{a}}$-absorption process because of the strong interaction between the hydroxyl groups of PVA and the hydrophilic imogolite surface. The in situ imogolite/PVA hybrid prepared by the in situ method exhibited excellent mechanical properties due to the fine dispersion of imogolite in the polymer matrix. The improvement of mechanical properties of crystalline polymer despite the decrease in crystallinity suggests the efficient reinforcing effect of imogolite nanofiber against the PVA matrix.

\section{CONCLUSION}

In this review, some procedures for the preparation of polymer hybrid with imogolite were described. By using surface modifier with both polymerizable units and phosphoric acid groups, PMMA/imogolite hybrid was successfully prepared. Pepsin/imogolite hybrid gel was prepared and well-characterized. Furthermore, in situ synthesis of imogolite in PVA solution gave mechanically improved hybrid materials that maintained their optical properties. Because imogolite is a naturally produced nanofiber and can also be artificially prepared, it appears to be a promising candidate for use as a-next generation environmentally benign nanofiller.

Acknowledgment. The authors express our sincere thanks to Prof. Shin-ichiro Wada (Faculty of Agricul- 
ture, Kyushu University) and Mr. Nozomi Inoue (Graduate School of Engineering) for their help to achieve the results obtained here. The present work was supported in part by a Grant-in-Aid for the 21st Century COE Program, "Functional Innovation of Molecular Informatics" from the Ministry of Education, Culture, Science, Sports and Technology of Japan, a Grant-in-Aid for Scientific Research $(A, 2)$ (No. 15205028), and Japan-Korea Basic Scientific Cooperation Program from Japan Society for the Promotion of Science. The authors also acknowledge the financial support of P\&P Green Chemistry of Kyushu University. The synchrotron radiation X-ray diffraction experiments were performed at SPring- 8 with the approval of JASRI as Nanotechnology Support Project (2004A0320-ND1b-np-Na) of the Ministry of Education, Culture, Sports, Science and Technology. K.Y. acknowledges the financial support of Grantin-Aid for JSPS Fellows.

\section{REFERENCES}

1. N. Yoshinaga and S. Aomine, Soil Sci. Plant Nutr., 8, 22 (1962).

2. P. D. G. Cradwick, V. C. Farmer, J. D. Russell, C. R. Masson, K. Wada, and N. Yoshinaga, Nature Phys. Sci., 240, 187 (1972).

3. J. Karube, Clays Clay Miner., 46, 583 (1998).

4. W. C. Ackrman, D. M. Smith, J. C. Huling, Y. W. Kim, J. K. Bailey, and C. J. Brinker, Langmuir, 9, 1051 (1993).

5. S. Imamura, T. Kokubu, T. Yamashita, Y. Okamoto, K. Kajiwara, and H. J. Kanani, Catalysis, 160, 137 (1996).

6. M. Suzuki, S. Suzuki, S. Tomura, M. Maeda, and T. Mizota, J. Ceram. Soc. Jpn., 109, 874 (2001).

7. H. Hoshino, T. Ito, N. Donkai, H. Urakawa, and K. Kajiwara, Polym. Bull., 29, 453 (1992).

8. K. Yamamoto, H. Otsuka, S.-I. Wada, and A. Takahara, J. Adhes., 78, 591 (2002).

9. S. Iijima, Nature, 354, 56 (1991).

10. A. B. Dalton, S. Collins, E. Munoz, J. M. Razal, V. H. Ebron, J. P. Ferraris, J. N. Coleman, B. G. Kim, and R. H. Baughman, Nature, 423, 703 (2003).

11. S. L. Ruan, P. Gao, Y. G. Yang, and T. X. Yu, Polymer, 44, 5643 (2003).

12. S. U. S. Choi, Z. G. Zhang, W. Yu, F. E. Lockwood, and E. A. Grulke, Appl. Phys. Lett., 79, 2252 (2001).

13. M. J. Biercuk, M. C. Llaguno, M. Radosavljevic, J. K. Hyun, A. T. Johnson, and J. E. Fischer, Appl. Phys. Lett., 80, 2767 (2002).

14. Z. Ounaies, C. Park, K. E. Wis, E. J. Siochi, and J. S. Harrison, Compos. Sci. Technol., 63, 1637 (2003).

15. T. Kashiwagi, E. Grulke, J. Hilding, R. Harris, W. Awad, and J. Douglas, Macromol. Rapid Commun., 37, 761 (2002).

16. F. Du, C. Guthy, T. Kashiwagi, J. E. Fischer, and K. I. Winey, J. Polym. Sci., Part B: Polym. Phys., 44, 1513 (2006).

17. C. Stephan, T. P. Nguyen, M. L. Chapelle, S. Lefrant, C.
Journet, and P. Bernier, Synth. Met., 108, 139 (2000).

18. D. Qian, E. C. Dickey, R. Andrews, and T. Rantell, Appl. Phys. Lett., 76, 2868 (2000).

19. A. Dufresne, M. Paillet, J. L. Putaux, R. Canet, F. Carmona, P. Delhaes, and S. Cui, J. Mater. Sci., 37, 3915 (2002).

20. A. R. Bhattacharyya, T. V. Sreekumar, T. Liu, S. Kumar, L. M. Ericson, R. H. Hauge, and R. E. Smalley, Polymer, 44, 2373 (2003).

21. J. C. Kearns and R. L. Shambaugh, J. Appl. Polym. Sci., 86, 2079 (2002).

22. M. S. P. Shaffer and A. H. Windle, Adv. Mater., 11, 937 (1999).

23. X. Zhang, T. Liu, T. V. Sreekumar, S. Kumar, V. C. Moore, R. H. Hauge, and R. E. Smalley, Nano Lett., 3, 1285 (2003).

24. N. Miyauchi and S. Aomine, Soil Sci. Plant Nutr., 12, 187 (1966).

25. H. Ray, R. H. Baughman, A. A. Zakhidov, and W. A. D. Heer, Science, 297, 787 (2002).

26. A. Thess, R. Lee, P. Nikolaev, H. J. Dai, P. Petit, J. Robert, C. H. Xu, Y. H. Lee, S. G. Kim, A. G. Rinzler, D. T. Colbert, G. E. Scuseria, D. Tomanek, J. E. Fischer, and R. E. Smalley, Science, 273, 483 (1996).

27. S.-I. Wada and Y. Kakuto, Soil Sci. Plant Nutr., 45, 947 (1999).

28. L. M. Johnson and T. J. Pinnavaia, Langmuir, 6, 307 (1990).

29. L. M. Johnson and T. J. Pinnavaia, Langmuir, 7, 2636 (1991).

30. K. Yamamoto, H. Otsuka, S.-I. Wada, and A. Takahara, Chem. Lett., 30, 1162 (2001).

31. K. Yamamoto, H. Otsuka, S.-I. Wada, D. sohn, and A. Takahara, Polymer, 46, 12386 (2005).

32. J. D. Russell, W. J. Mchardy, and A. R. Fraser, Clay Miner., 8, 87 (1969).

33. H. Ando, M. Nakahama, M. Yamamoto, K. Itoh, and M. Suzuki, Langmuir, 12, 6399 (1996).

34. M. Suzuki, A. Fujishima, T. Miyazaki, H. Hisamitsu, H. Ando, M. Nakahara, M. Yamamoto, and K. Itoh, J. Biomed. Mater. Res., 37, 252 (1997).

35. N. Donkai, T. Miyamoto, T. Kubota, and H. Tanei, J. Mater. Sci., 27, 6193 (1992).

36. N. Inoue, H. Otsuka, S.-I. Wada, and A. Takahara, Chem. Lett., 35, 194 (2006).

37. A. P. Philips and A. M. Wierenga, Langmuir, 14, 49 (1998).

38. J. Tang and B. S. Hartley, Biochem. J., 118, 611 (1970).

39. A. R. Sielecki, A. A. Fedrov, A. Boodhoo, N. S. Andreeva, and M. N. G. James, J. Mol. Biol., 214, 143 (1990).

40. A. Tiselius, G. E. Henschen, and H. Svensson, Biochem. J., 32, 1814 (1938).

41. L. A. Forato, R. Bernardes-Filho, and L. A. Colnago, Anal. Biochem., 259, 136 (1998).

42. D. G. Shchukin, G. B. Sukhorukov, R. R. Price, and Y. M. Lvov, Small, 1, 510 (2005).

43. S. Iijima and T. Ichihashi, Nature, 363, 603 (1993).

44. V. C. Farmer, A. R. Fraser, and J. M. Tait, J. Chem. Soc., Chem. Commun., 462 (1977).

45. G. H. Koenderink, S. G. J. M. Kluijtmans, and A. P. Philipse, J. Colloid Interface Sci., 216, 429 (1999).

46. F. Ohashi, S. Tomura, K. Akaku, S. Hayashi, and S.-I. Wada, J. Mater. Sci., 39, 1799 (2004). 
47. K. Yamamoto, H. Otsuka, S.-I. Wada, D. sohn, and A. Takahara, Soft Matter, 1, 372 (2005).

48. S.-I. Wada, A. Eto, and K. Wada, J. Soil Sci., 30, 347 (1979).

49. S. Krimm, C. Y. Liang, and G. B. B. M. Sutherland, J. Polym. Sci., 22, 227 (1956).

50. Y. Maniwa, R. Fujiwara, H. Kira, H. Tou, H. Kataura, S. Suzuki, Y. Achiba, E. Nishibori, M. Takata, M. Sakata, A. Fujiwara, and H. Suematsu, Phys. Rev. B: Condens. Matter Mater. Phys., 64, 241402/1 (2001).

51. V. C. Farmer, M. J. Adams, A. R. Fraser, and F. Palmieri,
Clay Miner., 18, 459 (1983).

52. K. Inoue and P. M. Huang, Soil Sci. Soc. Am. J., 50, 1623 (1986).

53. J. S. Shelley, P. T. Mather, and K. L. DeVries, Polymer, 42, 5849 (2001).

54. N. G. MaCrum, B. E. Read, and G. Williams, "Anelastic and Dielectric Effects in Polymeric Solids," John Wiley \& Sons, 1967, p. 327.

55. T. Tanigami, H. Hanatani, K. Yamaura, and S. Matsuzawa, Eur. Polym. J., 35, 1165 (1999).

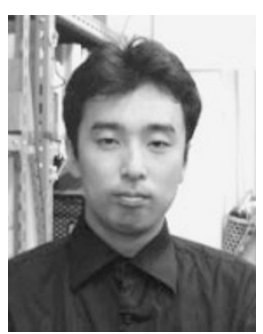

Kazuya Yamamoto was born in Saga, Japan in 1977. He received his Ph.D from Kyushu University under the supervision of Prof. Takahara in 2005. He was selected to a JSPS research fellow in 2004, and moved to National Institute of Standards and Technology, USA in 2005. In 2006 he joined Takahara's group again as a postdoctoral fellow, and he is currently working as research associate in Institute for Materials Chemistry and Engineering, Kyushu University.

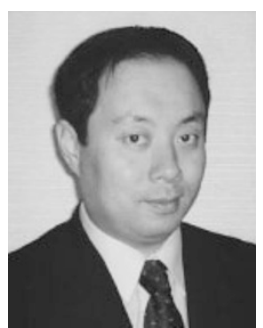

Hideyuki Otsuka was born in Fukuoka, Japan in 1969. He received his Ph.D in 1996 from Kyushu University under the supervision of Prof. Shinkai. He was selected to a JSPS research fellow in 1995, and moved to the University of Birmingham, UK in 1996. In 1997 he was appointed as a Research Associate in the laboratory of Prof. Endo, Tokyo Institute of Technology. In 2000 he was appointed as an Associate Professor at Kyushu University. He is one of the young scientists who received the "Young Scientist Award" from MEXT Japan in 2005. From 2006, he is a program officer of MEXT.

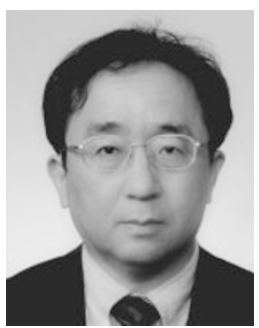

Atsushi Takahara received his Ph.D. in 1983 from Kyushu University, JAPAN. In 1999, he was appointed as a professor of Kyushu University and from 2003, he is a professor of Institute for Materials Chemistry and Engineering, Kyushu University. Since 2004, he is a program officer of JSPS (until March 2007), and from 2005, he is a member of the Science Council of Japan (SCJ)I. He received several awards including SPSJ Polymer Science Award (2003), Fiber Society Scientific Award (1999). His research interests include physical properties of polymer thin films, surface/interface science of organic solids, and polymer hybrids. 